University of Rhode Island

DigitalCommons@URI

Past Departments Faculty Publications (CELS) College of the Environment and Life Sciences

2005

\title{
Reservoir Competence of Native North American Birds for the Lyme Disease Spirochete, Borrelia burgdorferi
}

Howard S. Ginsberg

University of Rhode Island, hginsberg@uri.edu

P. A. Buckley

University of Rhode Island

Maxon G. Balmforth

University of Rhode Island

Elyes Zhioua

University of Rhode Island

Shaibal Mitra

University of Rhode Island

Follow this and additional works at: https://digitalcommons.uri.edu/cels_past_depts_facpubs

Creative Commons License

(c) (1) (8)

This work is licensed under a Creative Commons Attribution-Noncommercial 3.0 License

\section{Citation/Publisher Attribution}

Ginsberg, H. S., Buckley, P. A., Balmforth, M. G., Zhioua, E., Mitra, S., \& Buckley, F. G. (2005). Reservoir Competence of Native North American Birds for the Lyme Disease Spirochete, Borrelia burgdorferi. Journal of Medical Entomology, 4293), 445-449. doi: 10.1093/jmedent/42.3.445

Available at: https://doi.org/10.1093/jmedent/42.3.445

This Article is brought to you for free and open access by the College of the Environment and Life Sciences at DigitalCommons@URI. It has been accepted for inclusion in Past Departments Faculty Publications (CELS) by an authorized administrator of DigitalCommons@URI. For more information, please contact digitalcommonsgroup@uri.edu. 


\section{Authors}

Howard S. Ginsberg, P. A. Buckley, Maxon G. Balmforth, Elyes Zhioua, Shaibal Mitra, and Francine G.

Buckley 


\title{
Reservoir Competence of Native North American Birds for the Lyme Disease Spirochete, Borrelia burgdorferi
}

\author{
HOWARD S. GINSBERG,${ }^{1,2}$ P. A. BUCKLEY, ${ }^{1,3}$ MAXON G. BALMFORTH ${ }^{3}$ ELYES ZHIOUA,${ }^{2,4}$ \\ SHAIBAL MITRA, ${ }^{3,5}$ AND FRANCINE G. BUCKLEY ${ }^{3}$
}

U.S. Geological Survey Patuxent Wildlife Research Center, Coastal Field Station, Woodward Hall-PLS, University of Rhode Island, Kingston, RI 02881

\section{J. Med. Entomol. 42 (3): 445-449 (2005)}

\begin{abstract}
Reservoir competence for the Lyme disease spirochete, Borrelia burgdorferi, was tested for six species of native North American birds: American robin, gray catbird, brown thrasher, eastern towhee, song sparrow, and northern cardinal. Wild birds collected by mist netting on Fire Island, NY, were held in a field laboratory in cages over water and locally collected larval ticks were placed on the birds, harvested from the water after engorgement, and tested for infection by direct fluorescentantibody staining after molting to the nymphal stage. American robins were competent reservoirs, infecting $16.1 \%$ of larvae applied to wild-caught birds, compared with $0 \%$ of control ticks placed on uninfected laboratory mice. Robins that were previously infected in the laboratory by nymphal feeding infected $81.8 \%$ of applied larvae. Wild-caught song sparrows infected $4.8 \%$ of applied larvae and $21.1 \%$ when infected by nymphal feeding. Results suggest moderate levels of reservoir competence for northern cardinals, lower levels for gray catbirds, and little evidence of reservoir competence for eastern towhees or brown thrashers. Lower infection rates in larvae applied to wild-caught birds compared with birds infected in the laboratory suggest that infected birds display temporal variability in infectiousness to larval ticks. Engorged larvae drop from birds abundantly during daylight, so the abundance of these bird species in the peridomestic environment suggests that they might contribute infected ticks to lawns and gardens.
\end{abstract}

KEY WORDS reservoir competence, Borrelia burgdorferi, American robin, song sparrow, northern cardinal

THE PRIMARY RESERVOIR HOSTS for Lyme disease spirochetes Borrelia burgdorferi in the northeastern United States are rodents, especially the white-footed mouse, Peromyscus leucopus (Lane et al. 1991, Mather 1993, Piesman 2002). Mather et al. (1989b) showed that of three common mammal species at a site in Massachusetts, $P$. leucopus was the primary reservoir species. In the absence of $P$. leucopus, other rodents such as meadow voles, Microtus pennsylvanicus (Markowski et al. 1998), and even Norway rats, Rattus norvegicus (Smith et al. 1993), can serve as important reservoir hosts. Several studies have demonstrated varying degrees of reservoir competence in mammal species (Fish and Daniels 1990, Mather 1993), although some mammals (notably, white-tailed deer, Odocoileus vir-

\footnotetext{
${ }^{1}$ USGS Patuxent Wildlife Research Center, Coastal Field Station, University of Rhode Island, Kingston, RI 02881.

${ }^{2}$ Department of Plant Sciences, University of Rhode Island, Kingston, RI 02881.

${ }^{3}$ Department of Natural Resources Science, University of Rhode Island, Kingston, RI 02881.

${ }^{4}$ Current address: Institut Pasteur, Groupe Ecologie des Systèmes Vectoriels, 13 Place Pasteur, BP 74, 1002 Tunis-Belvedère, Tunisia.

${ }^{5}$ Current address: Department of Biology, College of Staten Island, 2800 Victory Blvd., Staten Island, NY 10314
}

ginianus) are clearly not competent reservoirs (Telford et al. 1988).

Relatively little attention has been paid to birds, which are generally considered secondary hosts that contribute relatively little to local transmission dynamics, except perhaps to dilute the force of transmission (LoGiudice et al. 2003). Several studies have recorded moderate-to-low infection prevalence in ticks removed from birds (Anderson and Magnarelli 1984, Weisbrod and Johnson 1989). However, infection rates in ticks removed from some wild-captured bird species have been comparable to ticks removed from mammalian reservoirs. For example, Rand et al. (1998) found that $43.5 \%$ of nymphs removed from American robins, Turdus migratorius, were positive by a direct fluorescent antibody procedure. Unfortunately, background infection rates in wild birds are generally unknown, and ticks removed from wildcaught birds might have acquired infection from unknown sources. Therefore, infection rates of ticks removed from wild birds are not, by themselves, reliable indicators of reservoir competence. Experimental evaluation of reservoir competence is essential. Richter et al. (2000) demonstrated in the laboratory that 
robins were competent reservoirs for B. burgdorferi. However, Mather et al. (1989a) found that gray catbirds, Dumatella carolinensis, were incompetent reservoirs. Thus, birds apparently vary in reservoir competence, perhaps similarly to mammals. Unfortunately, other than the two studies cited above (Mather et al. 1989a, Richter et al. 2000), there have been no experimental tests of reservoir competence in northeastern North American birds. To accurately assess the roles of birds in the natural transmission dynamics of B. burgdorferi, reservoir competence studies are needed for numerous additional bird species.

As part of a community-level study of B. burgdorferi transmission dynamics at a site on Fire Island, NY, we assessed reservoir competence of six species of common songbirds. Wild birds caught in mist nets were temporarily held in a field laboratory for the experiments, to provide conditions that were as natural as possible in controlled experimental tests of reservoir competence. In this article, we report infection rates in nymphal Ixodes scapularis (Say) that had been placed on these birds as larvae.

\section{Materials and Methods}

Birds were captured in nylon mist nets on Fire Island, a barrier island off the southern shore of Long Island, NY. The study site was at the Lighthouse Tract near the western end of the barrier island. Birds were captured in August 1997 and in July and August 1998 and were held for the term of each experiment in 38 by 38 by $48-\mathrm{cm}$ wire cages over water trays in a field laboratory (one room in a modified construction trailer). Ambient temperatures were maintained between 22.7 and $27.7^{\circ} \mathrm{C}$ and relative humidity was between 37 and $68 \%$. Birds were fed at 0800-1600 hours and maintained on a diet of wild blueberries (collected on site), a seed mix, waxworms, and mealworms (Grubco, Hamilton, $\mathrm{OH}$ ). Birds were weighed and food consumption was recorded daily. Any bird not eating or rapidly losing $>15 \%$ of its body weight was released.

Six bird species were tested for reservoir competence in 1997: American robin; gray catbird; eastern towhee, Pipilo erythrophthalmus; song sparrow, Melospiza melodia; northern cardinal, Cardinalis cardinalis; and brown thrasher, Toxostoma rufum. After capture, birds were deticked with fine forceps and/or by placing in cages over water and allowing attached ticks to drop. Ticks to be placed on birds were collected from the Lighthouse Tract with a white 1.0 by $0.5-\mathrm{m}$ pinwale corduroy flag. Larvae were applied to the head and neck areas of each bird over a white mat. The birds were placed in cages over water, and engorged ticks were retrieved from the water with a fine paintbrush, washed, dried, and placed in vials for transport to the laboratory at the University of Rhode Island. Ticks were collected each morning at $\approx 0630$ hours and each evening at $\approx 1930$ hours. Engorged larvae that dropped off the birds beyond $60 \mathrm{~h}$ after the flat larvae were applied were considered to be experimental ticks. Larvae that dropped off earlier might have been on the birds when captured, based on preliminary drop-off data (Balmforth 2002). The engorged larvae were kept at $22.5^{\circ} \mathrm{C}$ and $90 \% \mathrm{RH}$ until molting to the nymphal stage, at which point they were tested for infection with B. burgdorferi by direct fluorescent-antibody (DFA) staining. As a control, field-collected larvae were placed on uninfected $P$. leucopus (from a laboratory colony maintained at the University of Rhode Island), allowed to molt, and tested for B. burgdorferi infection by DFA. As a further test of background infection rates, free-living larvae collected from the study site from 1994 through 1997 were tested directly by DFA for infection with $B$. burgdorferi.

In 1998, robins and song sparrows were infected by application of field-collected nymphal ticks and were tested for reservoir competence by applying fieldcollected larvae, and testing for infection as in 1997. The robins were captured on 23-24 July, nymphs applied on days 1 through 5 of captivity, and larvae applied in two cohorts, 40 on day 10 and 100 on day 14 . This time period was sufficient to allow spirochetemia to develop in birds and transmission to occur (Piesman et al. 1996, Richter et al. 2000). The song sparrows were captured on $25 \mathrm{July}$, and a total of 95 nymphs and 195 larvae were applied in approximately equal numbers to each bird on $3 \mathrm{~d}$ (larvae and nymphs together each day) on days 4 through 10 of captivity (also, 50 larvae were applied to one of the birds on day 2 to determine whether larvae could be infected when simultaneously feeding with nymphs).

The DFA procedure involved squeezing the tick midguts and hemolymph onto glass slides (the cuticles were discarded), incubating for at least $2 \mathrm{~h}$ at $34^{\circ} \mathrm{C}$, cleaning with acetone for $10 \mathrm{~min}$ and then staining with 1:10 diluted, fluorescein isothiocyanate-conjugated anti-B. burgdorferi goat antibody (KPL, Gaithersburg, MD). The slides were incubated at $34^{\circ} \mathrm{C}$ until dry and washed twice (5 min each) with phosphatebuffered saline (PBS) and then with distilled water. When dry, the slides were mounted with a 9:1 solution of glycerol and PBS and then examined under a fluorescent microscope at $400 \times$ for evidence of B. burgdorferi.

\section{Results}

Table 1 presents information on the birds used in the reservoir competence experiments. American robins showed evidence of reservoir competence in the 1997 trials (Table 2). Northern cardinals, song sparrows, and gray catbirds also showed evidence of reservoir competence but at lower levels than robins, and the evidence is less reliable because of small sample sizes. Note that none of the control larvae placed on uninfected mice were positive as nymphs (Table 2). Furthermore, of 1,333 free-living larvae collected at the site from 1994 through 1997 and tested for infection by DFA (446 of these in 1997), none were positive.

Some of the birds might not have been infected at the time of the experiment. If we consider only ticks 
Table 1. Birds used in reservoir competence studies

\begin{tabular}{|c|c|c|c|c|}
\hline Species & No. individuals & Dates of trials & Mean no. days held ${ }^{a}$ & Mean $\%$ wt change \\
\hline \multirow[t]{2}{*}{ American robin } & 4 & 12-23 Aug. 1997 & 5.0 & -15.3 \\
\hline & 5 & 23 July-12 Aug. 1998 & 16.6 & +0.9 \\
\hline \multirow[t]{2}{*}{ Gray catbird } & 9 & 2-22 Aug. 1997 & 4.2 & -12.7 \\
\hline & 3 & 24 July-3 Aug. 1998 & 9.7 & +4.0 \\
\hline \multirow[t]{2}{*}{ Song sparrow } & 6 & 7-22 Aug. 1997 & 4.7 & -2.6 \\
\hline & 3 & 25 July-9 Aug. 1998 & 16.0 & -0.7 \\
\hline Brown thrasher & 1 & 7-10 Aug. 1997 & 4 & -5.5 \\
\hline Eastern towhee & 7 & 7-22 Aug. 1997 & 5.0 & -6.4 \\
\hline Northern cardinal & 2 & 7-22 Aug. 1997 & 5.5 & +1.0 \\
\hline
\end{tabular}

${ }^{a}$ Includes day of capture and day of release.

that had attached to birds from which at least one positive tick was recovered (i.e., from birds that we know were infected), then $33.3 \%$ of the ticks from infected robins and $22.2 \%$ of the ticks from infected cardinals were infected. If all ticks that dropped off the bird are considered, including those attached to the bird when captured, 13 of 25 larvae recovered from two infected robins were infected (52\% positive).

In 1998, at least 30 nymphs were applied to each of four robins and three song sparrows, and infected nymphs were recovered from each bird. Therefore, all of these birds had been exposed to B. burgdorferi. Infection in free-living larvae, after feeding on these birds and molting to the nymphal stage, is shown in Table 3. Larvae picked up infection from all four robins and from two of the three song sparrows. Infection rates were consistently high in ticks recovered from infected robins (range 69.2-100\% from individual birds) but varied considerably in ticks from the song sparrows (range $0-53.8 \%$ of ticks from different birds).

The numbers of engorged larvae collected from water beneath the cages at 6:30 a.m. (these ticks had dropped off the previous night) and at 7:30 p.m. (these ticks had dropped of during the day) are shown in Table 4. There was a tendency toward greater drop-off during the day (Wilcoxon signed ranks test for paired observations, two-tailed; 1997, $t_{\mathrm{s}}=-1.992, P=0.023$; $\left.1998, t_{\mathrm{s}}=-1.604, P=0.054\right)$, but ticks dropped from birds abundantly during both day and night.

Table 2. Reservoir competence trials for B. burgdorferi, Fire Island, NY

\begin{tabular}{lccc}
\hline \hline \multicolumn{1}{c}{ Species } & Yr & $\begin{array}{c}\text { No. larvae } \\
\text { tested }\end{array}$ & $\begin{array}{c}\text { No. positive } \\
(\%)\end{array}$ \\
\hline American robin & 1997 & 31 & $5(16.1)$ \\
Gray catbird & 1997 & 50 & $2(4.0)$ \\
Song sparrow & 1998 & 6 & $1(16.7)$ \\
Brown thrasher & 1997 & 42 & $2(4.8)$ \\
Eastern towhee & 1997 & 8 & 0 \\
Northern cardinal & 1997 & 56 & $1(1.8)$ \\
Uninfected mice $^{a}$ & 1997 & 23 & $2(8.7)$ \\
\hline
\end{tabular}

${ }^{a}$ White-footed mice from laboratory colony used as controls for possible infection in free-living larval ticks.

\section{Discussion}

Some bird species are competent reservoirs of $B$. burgdorferi. Our results corroborate the findings of Richter et al. (2000) that American robins are highly competent reservoirs of $B$. burgdorferi, and we provide evidence that some other common species, including song sparrows and northern cardinals (Stafford et al. 1995) can serve as reservoirs as well. Gray catbirds, which are generally not considered competent reservoirs (Mather et al. 1989a, Rand et al. 1998), also showed some indication of reservoir competence in our trials (Table 2) and deserve further study. This is the first study using wild-caught birds and field-collected larval ticks to assess reservoir competence of several bird species in controlled trials.

The reservoir competence of robins that had been previously infected by attached nymphs (Table 3 ) was comparable with that reported for the white-footed mouse, the primary reservoir of Lyme disease in northeastern North America (Donahue et al. 1987, Mather et al. 1989b). However, infection levels were lower in ticks placed on wild-caught birds without prior laboratory infection (Table 2), suggesting either that many wild birds are not infected or that infectivity varies through time, relative to the time of initial infection. In the results from ticks from naturally infected wildcaught birds, if we include only those birds that produced at least one infected tick (so we know that all of these birds were infected), only one-third of the larvae from these birds were infected as nymphs. Compare that with $81.8 \%$ of ticks that were infected from birds that we had infected in the laboratory by nymphal feeding. Thus infectivity was lower in naturally infected than in laboratory-infected birds, perhaps due to fluctuations in infectivity through time. Donahue et al. (1987) and Burgdorfer and (Schwan

Table 3. Reservoir competence trials for B. burgdorferi on laboratory-infected birds, Fire Island, NY, 1998

\begin{tabular}{lcccc}
\hline \hline \multicolumn{1}{c}{ Species } & $\begin{array}{c}\text { No. } \\
\text { birds }\end{array}$ & $\begin{array}{c}\text { No. larvae } \\
\text { tested }\end{array}$ & $\begin{array}{c}\text { No. } \\
\text { positive }\end{array}$ & $\begin{array}{c}\% \\
\text { Positive }\end{array}$ \\
\hline American robin $^{a}$ & 4 & 55 & 45 & 81.8 \\
Song sparrow $^{b}$ & 3 & 38 & 8 & 21.1 \\
\hline
\end{tabular}

\footnotetext{
${ }^{a}$ Nymphs were placed on robins 5-14 d before larvae.

${ }^{b}$ Nymphs and larvae were placed on sparrows simultaneously three times during a 6 -d period.
} 
Table 4. Drop-off times of $I$. scapularis larvae from birds

\begin{tabular}{lcrrrr}
\hline \multirow{2}{*}{\multicolumn{1}{c}{ Bird species }} & \multicolumn{2}{c}{1997} & & \multicolumn{2}{c}{1998} \\
\cline { 2 - 3 } \cline { 5 - 6 } & Day & Night & & Day & Night \\
\hline American robin & 34 & 10 & & 58 & 42 \\
Gray catbird & 42 & 19 & & 7 & 5 \\
Brown thrasher & 14 & 2 & & 26 \\
Eastern towhee & 57 & 31 & & & \\
Song sparrow & 46 & 20 & & 33 & \\
Northern cardinal & 17 & 19 & & \\
\hline
\end{tabular}

1991) reported temporal changes in infectivity by $P$. leucopus in the laboratory, but ticks from field-collected mice typically have high infection rates (Mather 1993). Variability in infectivity also was apparent in our trials between individuals of some bird species. Among song sparrows, for example, individual infected birds were infectious to anywhere from 0 to $>50 \%$ of attached larvae. However, the simultaneous application of nymphs and larvae to song sparrows over a 6-d period might account, in part, for this variability. In our trials with American robins (which displayed more consistent infectivity), larval ticks were applied 5-14 d after application of nymphs.

Despite variability in infectivity, birds can function as reservoirs of $B$. burgdorferi. However, assessing their importance to human risk of disease is more complicated. The relatively low infection prevalence in larval ticks from wild-caught birds compared with ticks from wild-caught mice suggests that birds contribute less than mice to infection in nymphal ticks in endemic areas. A full assessment, however, would require that the relative numbers of ticks that attach to each vertebrate species be quantified. This calculation is complicated by the large numbers of birds that pass through coastal areas on their southward migrations in late summer and fall. Even if these birds have small tick burdens, their large numbers could result in substantial contributions to local tick populations in coastal areas.

The importance of birds versus mammals as reservoirs of $B$. burdgorferi also depends on the duration of infectivity. Richter et al. (2000) found that infectivity in robins declined after 2 mo. The lower infection rate in nymphs that had fed as larvae on newly caught versus laboratory-infected robins in our study suggests that infectivity in the field might be compromised by other factors in wild birds. The relatively high infection rates in larvae collected from wild-caught $P$. leucopus (Mather 1993) suggest that mice typically play a greater role than birds as reservoirs in natural areas.

Assessing the importance of birds to human risk of Lyme disease, however, also requires an evaluation of whether the ticks on birds are more or less likely to encounter humans than ticks from mammalian hosts. Exposure to Lyme disease is primarily peridomestic (Maupin et al. 1991), so the contribution of birds relative to mammals to tick infection around human dwellings is critical. The birds demonstrating reservoir competence in our study include robins, cardinals, and song sparrows, which frequently use backyard environments and some of which are commonly seen at bird feeders. Therefore, they are likely to drop engorged larvae in lawns and gardens, where ticks are less common than in woods and at wood edges (Maupin et al. 1991, Carroll et al. 1992) but more likely to encounter people. Ticks drop abundantly from birds during daylight (Table 4), so many of these engorged larvae are undoubtedly dropped in peridomestic environments. Battaly and Fish (1993) documented the importance of American robins (along with house wrens and common grackles) as potential sources of ticks on lawns in Westchester County, New York. Engorged larvae dropping from birds on lawns would have to survive through the winter and successfully molt to the nymphal stage before they might attach to a human, and it is not clear whether this can occur in the relatively exposed environment around human dwellings. Survival of nymphs is low in open habitats (Ginsberg and Zhioua 1996). Nevertheless, the contribution of birds to human infection in the peridomestic environment could be substantial and deserves further study.

\section{Acknowledgments}

We thank the National Park Service staff at Fire Island National Seashore for continued support. This work was funded by the National Biological Service and the U.S. Geological Survey, with support from the National Park Service and the University of Rhode Island.

\section{References Cited}

Anderson, J. F., and L. A. Magnarelli. 1984. Avian and mammalian hosts for spirochete-infected ticks and insects in Lyme disease foci in Connecticut. Yale J. Biol. Med. 57: 627-641.

Balmforth, M. G. 2002. Experimental examination of the reservoir competence of six species of native North American songbirds for the Lyme disease pathogen, Borrelia burgdorferi. M.S. thesis, University of Rhode Island, Kingston, RI.

Battaly, G. R., and D. Fish. 1993. Relative importance of bird species as hosts for immature Ixodes dammini (Acari: Ixodidae) in a suburban residential landscape of southern New York,. J. Med. Entomol. 30: 740-747.

Burgdorfer, W., and T. G. Schwan. 1991. Lyme borreliosis: a relapsing fever-like disease? Scand. J. Infect. Dis. Suppl. 77: $17-22$

Carroll, M. C., H. S. Ginsberg, K. E. Hyland, and R. Hu. 1992. Distribution of Ixodes dammini (Acari: Ixodidae) in residential lawns on Prudence Island, RI. J. Med. Entomol. 29: 1052-1055

Donahue, J. G., J. Piesman, and A. Spielman. 1987. Reservoir competence of white-footed mice for Lyme disease spirochetes. Am. J. Trop. Med. Hyg. 36: 92-96.

Fish, D., and T. J. Daniels. 1990. The role of medium-sized mammals as reservoirs of Borrelia burgdorferi in southern New York. J. Wildl. Dis. 26: 339-345.

Ginsberg, H. S., and E. Zhioua. 1996. Nymphal survival and habitat distribution of Ixodes scapularis and Amblyomma americanum ticks (Acari: Ixodidae) on Fire Island, New York, USA. Exp. Appl. Acarol. 20: 533-544.

Lane, R. S., J. Piesman, and W. Burgdorfer. 1991. Lyme borreliosis: relation of its causative agents to its vectors 
and hosts in North America and Europe. Annu. Rev. Entomol. 36: 587-609.

LoGiudice, K., R. S. Ostfeld, K. A. Schmidt, and F. Keesing. 2003. The ecology of infectious disease: effects of host diversity and community composition on Lyme disease risk. Proc. Natl. Acad. Sci. U.S.A. 100: 567-571.

Markowski, D., H. S. Ginsberg, K. E. Hyland, and R. Hu. 1998. Reservoir competence of the meadow vole (Rodentia: Cricetidae) for the Lyme disease spirochete, Borrelia burgdorferi. J. Med. Entomol. 35: 804-808.

Mather, T. N. 1993. The dynamics of spirochete transmission between ticks and vertebrates, pp. 43-60. In H. S. Ginsberg [ed.], Ecology and environmental management of Lyme disease. Rutgers University Press, New Brunswick, NJ.

Mather, T. N., S. R. Telford III, A. B. MacLachlan, and A. Spielman. 1989a. Incompetence of catbirds as reservoirs for the Lyme disease spirochete. J. Parasitol. 75: 66-69.

Mather, T. N., M. L. Wilson, S. I. Moore, J.M.C. Ribeiro, and A. Spielman. 1989b. Comparing the relative potential of rodents as reservoirs of the Lyme disease spirochete (Borrelia burgdorferi). Am. J. Epidemiol. 130: 143-150.

Maupin, G. O., D. Fish, J. Zultowski, E. G. Campos, and J. Piesman. 1991. Landscape ecology of Lyme disease in a residential area of Westchester County, New York. Am. J. Epidemiol. 133: 1105-1113.

Piesman, J. 2002. Ecology of Borrelia burgdorferi sensu lato in North America. pp. 223-249. In J. Gray, O. Kahl, R. S. Lane, and G. Stanek [eds.], Lyme borreliosis: biology, epidemiology and control. CABI Publishing, Oxon, United Kingdom.

Piesman, J., M. C. Dolan, M. E. Schiefer, and T. R. Burkot. 1996. Ability of experimentally infected chickens to infect ticks with the Lyme spirochete, Borrelia burgdorferi. Am. J. Trop. Med. Hyg. 54: 294-298.

Rand, P. W., E. H. LaCombe, R. P. Smith, and J. Ficker. 1998. Participation of birds (Aves) in the emergence of Lyme disease in southern Maine. J. Med. Entomol. 35: 270-276.

Richter, D., A. Spielman, N. Komar, and F. R. Matuschka. 2000. Competence of American robins as reservoir hosts for Lyme disease spirochetes. Emerg. Inf. Dis. 6: 133-138.

Smith, R. P., Jr., P. W. Rand, E. H. LaCombe, S. R. Telford III, S. M. Rich, J. Piesman, and A. Spielman. 1993. Norway rats as reservoir hosts for Lyme disease spirochetes on Monhegan Island, Maine. J. Infect. Dis. 168: 687-691.

Stafford, K. C., III, V. C. Bladen, and L. A. Magnarelli. 1995 Ticks (Acari: Ixodidae) infesting wild birds (Aves) and white-footed mice in Lyme, CT. J. Med. Entomol. 32: 453- 466.

Telford, S. R., III, T. N. Mather, S. I. Moore, M. L. Wilson, and A. Spielman. 1988. Incompetence of deer as reservoirs of the Lyme disease spirochete. Am. J. Trop. Med. Hyg. 39: 105-109.

Weisbrod, A. R., and R. C. Johnson. 1989. Lyme disease and migrating birds in the Saint Croix River valley. Appl. Environ. Microbiol. 55: 1921-1924.

Received 10 December 2004; accepted 17 February 2005 